\title{
Admixtures in backfill applications for cost and performance benefits
}

\author{
Z. Martic BASF Construction Chemicals, MEYCO Global Underground Construction, Switzerland
}

J.E. Gelson BASF Construction Chemicals, MEYCO Global Underground Construction, Australia

J. Champa BASF Construction Chemicals, MEYCO Global Underground Construction, USA

B. Knight BASF Construction Chemicals, MEYCO Global Underground Construction, Canada

\begin{abstract}
The use of chemical admixtures in mining backfill operations is not new historically but the widespread use of chemical admixtures in the backfill industry is still relatively uncommon. The successful use of admixtures in various projects globally is not well documented or known, and this knowledge is basically confined to a very small specific group. These successful references have not facilitated the introduction of admixtures in backfill plants on a regular basis. Various reasons for not using admixtures as an integral part of backfill systems and operations are often related to additional material costs rather than considering the total benefits to the mine, not just the backfill operations. BASF (previously known as Master Builders) showed in the early 1990s that certain properties of the fill can be significantly improved by the use of chemical admixtures. What was not followed or expanded upon were the benefits to the mine of the backfill mix design in terms of rheology, strength increase, reduced pipeline pressures and potential binder savings. At that time, often the instrumentation and monitoring of backfill was relatively unsophisticated and hence improvements were hard to quantify. With the use of modern transducers, sensors, flow meters etc., key parameters are much easier to quantify, and hence show the potential greater benefits of admixtures in backfill mixes to the total mining system. The paper sets out to show the benefits from the use of chemical admixtures in backfill mixes, and through case histories and measurements, quantify the real improvements both physical and financial for the backfill industry. It will also show how a backfill admixture can be a useful tool to improve various parameters of the fill. The authors' aim in this paper is to hopefully show a creative method and approach to using admixtures in a backfill system rather than to simply discuss the results of a particular admixture application.
\end{abstract}

\section{Introduction}

Historically, admixtures found their place in backfill a long time ago, but the trend of large-scale incorporation of admixtures into the backfill industry started a relatively short time ago. In the past, admixtures were sporadically and successfully used in many projects for specific needs and purposes. They were mainly used as an adequate response to difficult challenges, being the only viable solution. These success stories still did not lead to a wider introduction of admixtures into backfill plants on a regular basis (as in continuous pour operations, as part of standard mix design). The reasons for not using admixtures as an integral part of backfill systems and operations are of different origins. Different types of admixtures were used to respond to challenges in rheology and to improve in situ properties but mostly were used for binder optimisation and/or as a pumping aid. Different types of admixtures are currently available on the market, but little is widely known on how they can be optimally used in the mining industry.

Admixtures can physically be either liquids or powders, their composition may be mono- or multicomponent (two or more different admixtures blended into one), to perform different tasks (Ramachandran, 1995). The chemical design of an admixture will depend on the application conditions and requirements, but also needs to be a safe and stable product. The mono-component or multi-component type admixtures ultimately depend on the desired goal that is required for a specific project - tailor made admixtures (e.g. a superplasticising admixture with a retarder or with a pumping aid). For simplification it is possible to divide chemical admixtures into the following basic groups based on their function: 
- water reducers: low range, mid range, high range and super/hyperplasticisers

- retarders: of varying strength

- viscosity modifying admixtures

- accelerators

- pumping aids

- admixtures for very specific purposes such as: anti-wash out, anti-build up, flushing help, etc.).

The purpose of this paper is to explain the concepts, rather than to discuss a specific product and the associated chemical details. Some admixtures are mentioned as examples from existing applications. An improved understanding of material properties and processes is necessary for the optimal and efficient employment of an admixture in the backfill operation. Only then can one maximise the tangible benefits of chemical admixtures. Appropriate admixture use can lead to major benefits in the fill; conversely inappropriate use of admixtures can be costly and provide no technical gains which have unfortunately happened in the past. It also has to be noted that in certain backfill mixes, admixtures may not assist or be an economic solution. Each mine is therefore very specific and indeed there are often variations in such things as tailings mineralogy at the same mine.

\section{History}

BASF (Master Builders at that time) showed in the early 1990s that the properties and cost of backfill can be significantly improved by using admixtures (Farzam et al., 1998; Gay and Constantiner, 1998; Wang et al., 2002; Klein and Simon, 2006a, 2006b). This, however, was not followed by any significant changes to, or growth in the use of admixtures in standard backfill mix designs. One of the key reasons for a lack of growth in the use of admixtures was cement price.

Historically, cement prices were much lower than they are now (at the end of the 1990s, the cement price in North America was around $\$ 80 / \mathrm{t}$ and slag and fly ash were significantly cheaper compared to today's prices). This made the economic benefits of admixtures in backfill often hard to justify.

Another explanation is that the elements for control and regulation of the backfill mix available and incorporated in the process at that time (sensors, flow meters, etc.) were at a level that could not provide a high degree of accuracy of measurement or confidence in the recorded data. The results of measurements could not clearly differentiate a significant advantage in using admixtures and thus could not present a justification for the benefits of using admixtures in backfill operations.

At the time, backfill requirements in the majority of mines were basically managed and understood only via the geomechanics/mining engineering groups. After all, backfill was a means of ground support and hence the geotechnical group along with the mining engineer would provide the technical parameters and phasing of backfill operations. Little has changed and rightly so, but of course none of these technical groups have a clear understanding of cement technology, or tailings chemistry. Hence the chemistry side of the backfill operation was at a basic level compared to the geotechnical side.

Backfill systems were observed, analysed and approached mostly as a physical system and a physical solution was a logical part of the final concept/solution. Chemistry of tailings and binder chemistry was of secondary interest, even though this area represents one of the highest ongoing costs to the mine.

Chemical companies in the early days considered backfill as a simple low strength concrete type process and also failed to closely examine holistically the tailings mineralogy, process water and other more miningrelated factors.

Hence the potential chemical solutions via admixtures were really never integrated properly with the backfill process and resulted in only partial successes. This is a subjective statement by the authors from their experience with backfill and limited contacts with the mines at that time.

BASF now undertake systematic research and evaluation on all the varying parameters of a mine's backfill system to determine whether chemical solutions are both feasible and economic. This complete approach is showing benefits and is definitely the way forward. 
Several projects using admixtures in backfill were documented and presented in the past regarding the importance of cement chemistry (Farzam et al., 1998; Gay and Constantiner, 1998; Wang et al., 2002; Nieminen and Seppanen, 1983; Thomas, 1973) but these have not had a big impact on the growth of admixture usage in the backfill market.

Major statements, as quoted below by Professor Will Bowden (Donovan et al., 2007), have clearly shown the potential benefits of admixtures in backfill, but this belief needs to be more fully adopted in the industry globally. This can only occur via a total professional systematic approach by the chemical company.

"Unconfined compressive strength [UCS at 90 days] values varying from about 5 to 5.8 MPa were measured. Additional UCS sampling was done at the David Bell Mine during this time. The results of the on-site surface and underground testing can be found in Figure \# 13 (Reproduced here as Figure 1). A design UCS of about 4 MPa is considered reasonable. It is interesting that this strength is $\sim$ two times higher than the original recommended design strength of 2.0 MPa. This high strength appears to be related to the addition of the PS 1466 admixture per tonne of paste fill" Donovan et al. (2007)

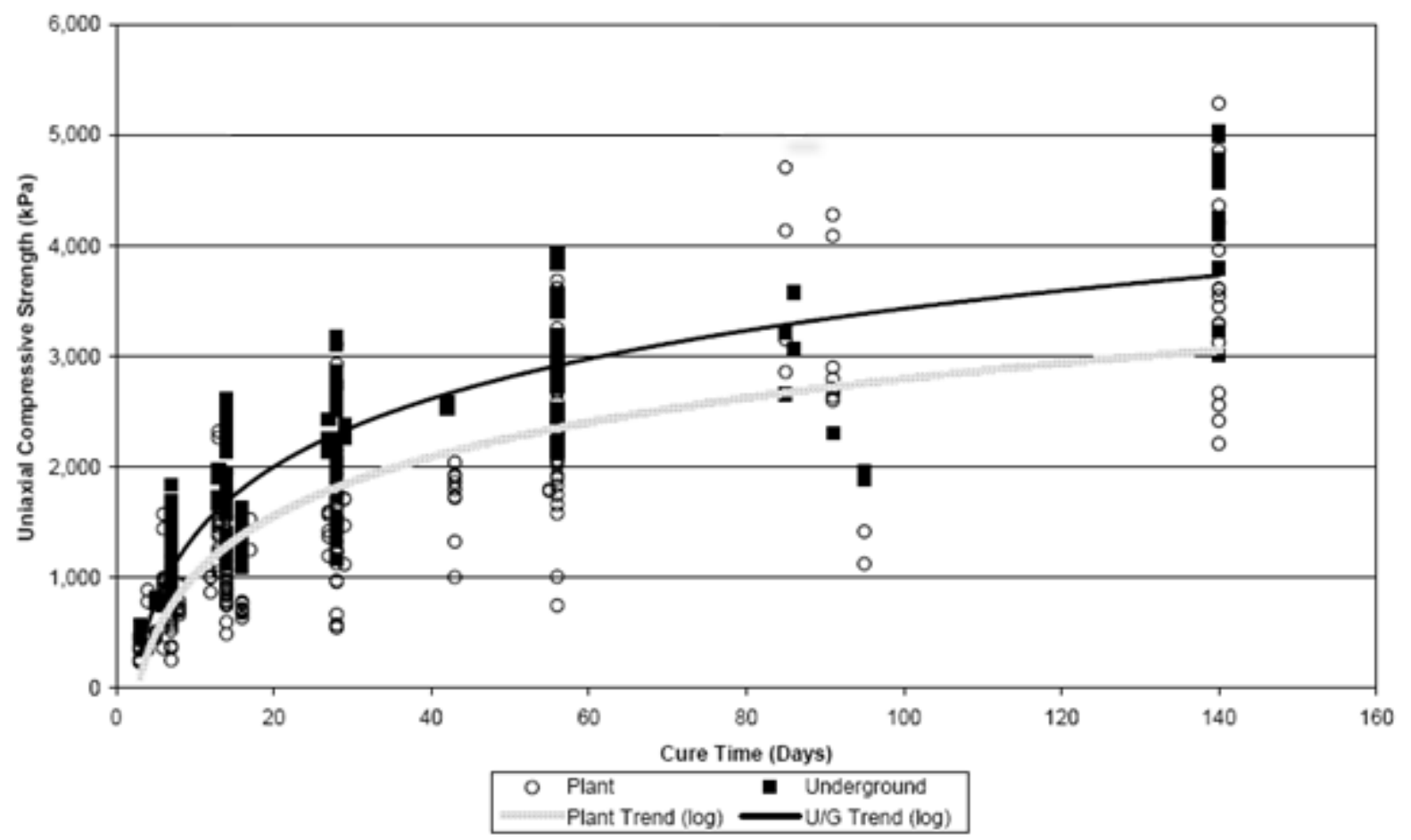

Figure 1 Paste fill strength development (6\% Cement + 6\% Fly ash + $600 \mathrm{~mL}$ PS 1466/tonne)

"The most interesting issue to date is the significant strength increase in the fill, apparently resulting from application of the PS 1466 admixture [BASF, Degussa Master Builders]."

Donovan et al. (2007)

It is evident from the results that the admixture had a positive impact on the strength of the fill. It is important as well to understand that this admixture was "customised" for this project and may not be appropriate or effective in another backfill operation. Each backfill operation needs a detailed approach in material characterisation and technical analysis and evaluation. Only then can admixtures be tested, evaluated and proposed for a specific project. This is the present course of BASF and their MEYCO Underground group in backfill.

\section{$3 \quad$ Backfill as a system}

Backfill operations are often complex systems, which may not be immediately apparent at first sight. We now know that backfill is a multi-disciplinary science which requires experts in different fields to understand 
and describe all of the technical aspects and co-relationships occurring in the various parts of backfill processes and operations.

The specific needs and complexities of backfill, demand multi-disciplinary knowledge, and multi-level correlations are required to bring the pieces of the puzzle all together. This can then be utilised to produce the entire picture not only for a backfill operation but also for an entire system (for the total mining cycle). Better understanding of backfill assumes, besides technical knowledge, a good understanding of economics. In order to understand properly the complexity and multi-interaction of components in a backfill system, it is practical to break the system down and do an analysis of each segment, one by one, before we make a crosslink and further compare it again in order to get the best effective solution. Belem and Benzaazoua (2007) stated that segmentation can help us to investigate and correlate often complex systems. Hence by breaking down a complex process into smaller simpler steps, an analysis is much easier to undertake.

Rheology of the backfill paste has been a subject of many projects and it is quite well investigated. From an admixture viewpoint, focus has been mainly on very specific fills and the effects of admixtures on their rheology. The main focus has been in presenting achievements rather than discussing the entire backfill system and benefits of admixtures in different areas, not just on rheology. In this paper the authors would like to present a different view as to the use of admixtures in backfill.

Firstly it is appropriate to review some basics of backfill rheology. It is a complex subject, as the fill rheology is determined by many inter-related physical and chemical factors. For these reasons, simplification is not always easy. It is obvious that solids content is a major factor, but we have to look much deeper and analyse the individual constituents of the mix design:

- Firstly some of the determining factors include the solid material properties (sand, tailings etc.), such as particle size distributions (PSD), solid density, surface chemistry, particle shape, oxidation of minerals, presence of clays, etc.

- Secondly the binder properties (PSD, surface area, reactivity, etc.).

- Thirdly the water source, which determines the inherent water properties (chemistry, additives present, salts, temperature, etc.).

All of these parameters can independently influence the fill rheology in different and variable ways. They can also interact amongst themselves creating new and unexpected rheology correlations. For example, some minerals can retard binder reactivity and some can accelerate it, and ions in the process water can also do the same. Some ions present can flocculate binder and therefore produce stiffened paste, some ions can naturally disperse binder particles and therefore can have a positive influence on flow properties of the fill. Determining influence of one parameter for an isolated system can help in estimation but could not lead to a general rule. "One case doesn't make a rule" and for backfill it is not appropriate to make general conclusions out of a couple of studies.

It is not possible to control everything in the backfill system by one single parameter or a group of parameters. Mechanical parameters alone cannot in many cases fully optimise a fill system. This is where the chemical solution can often be used to enhance the efficiency of the fill system.

We have seen that materials (particularly tailings) will vary from mine to mine and from operation to operation, which is what makes backfill very specific and challenging. Some rules and conclusions however can be used at least as a guide for further investigation and new projects.

Most backfill operations use tailings and available sands with poor material properties for fill purposes. The aggregates, sand and tailings are not fully engineered materials, as they are in the concrete industry, hence the physical characteristics of the base products do not lend themselves to create high strengths and good flow in many backfill mixes.

In concrete manufacture, the PSDs of aggregates and sands are purely engineered for concrete and mortar but this is not the case for backfill. Material used for backfill is often nearby available material, often even degraded materials for economical reasons; a good example is tailings dewatered by hydrocycloning.

Dewatering by hydrocycloning provides a relatively cheap and fast operation to the upgrading of solids content but also is an imprecise method that will also remove many fines from the fill. The final product will 
be a coarser fraction that is poorly graded. This material will now require more water to become fluid and will require more binder to gain the required strength - the material will have a lot of voids which will need filler and binding agents to bridge the gap. As a more porous material, this fill will lose water easily, or drain quickly once placed, which is desirable, however it will also lose a lot of binder fines too which is very undesirable.

Mineral composition and surface chemistry of the main backfill material (tailings, sand, aggregates or rocks) will largely define the rheology, cement hydration and in situ properties. Source of material can significantly influence properties of the fill.

Dry excavated tailings with highly oxidised surfaces in paste-fill systems will certainly change the fill properties as compared to a fresh tailings stream. In a backfill system with high solid content and significant stress-attrition (during mixing and transport), the resulting paste made from dry tailings can generate a significant concentration of ions, which can have an impact on the cement hydration process (coating, retardation or acceleration).

The weathered (or oxidised) tailings in the system described above will certainly change mechanically during the transportation as compared to fresh tailings. The degree of degradation will be varied but not negligible from case-to-case. This phenomenon could be related to the existence and formation of oxide minerals or clays in this type of tailings. The effect of these minerals in the fill is mostly negative and their influences on the fill properties are unpredictable. For this reason, a simplified and unique mechanical approach will not be sufficient nor lead to the best solution. Hence, an understanding of the chemistry is required to provide an overall understanding, before any chemical solution can be sought.

Cement properties are often poorly known and controlled even though they play a key role both for flowability and for strength development in backfill operations. Cement chemistry knowledge is complex and possibly the least understood on a mine site. Blended cements are mostly determined by price and not optimised for specific backfill operational needs. To our knowledge, there are insufficient works and articles dedicated to this area of interest in backfill practice, i.e. understanding the correlation between backfill properties and specific binders used. Some papers on binder effects are available as guide lines, such as Archibald et al. (1995), Aylmer (1973) and Yu and Counter (1988), however, more work is required to effectively build up a data bank of references.

We can state from our experience that binder efficiency will depend very much on tailings, water and internal chemistry of the binder, as well as on some process characteristics (equipment for mixing, transportation distance, temperature, etc.). Major differences are also apparent in the way admixtures work on different cements.

Water in the backfill process will have some site specific properties. These chemical properties are related to some of the processes of mineral extraction (mineral processing) and/or can be related to the original water source. Some original water sources can be very high in dissolved solids from underground mines or boreholes.

Complexity of water used can be related to dissolved salts, reagents from mineral processing, colloidal particles, temperature, etc. In our practice, we have seen that water can significantly change flow properties of fill and the hydration of binders, and also performances of some admixtures (generally in a negative way rather than positive). For this reason, any admixture testing in backfill applications must include the actual process water from the plant. Many admixtures have shown sensitivity to water quality for this reason, hence the desire for new reliable products in the future.

\section{$4 \quad$ Admixtures}

Each admixture can have a different purpose, but even the same admixture can have multiple practical applications. A good example of this is a superplasticiser, which can be used not only in binder optimisation and strength optimisation but also in time optimisation. The requirements or parameters in the backfill system may be fixed or variable with regards to set times and strength in a stope for example. Furthermore, the superplasticiser can be seen also as a rheology modifying admixture, as it will improve flowability. For these reasons, admixtures should be considered as multi-task and multi-aspect tools. The various types of admixtures used in backfill systems today are becoming more and more sophisticated. 
It is important to understand that various admixture combinations are possible and required from time to time and from system to system.

Requirements in mixing, pumping, placement but as well, in situ strength requirements, could be different and can be contradictory with each other regarding fill properties. Acceleration and retardation of fill strengths can also be achieved with multi-role admixtures.

If we can analyse separate parts of a system we can come to the optimal solution for each part. It is relatively easy to find a solution for one aspect, say flowability, however when used in the total system we may find segregation occurs in horizontal lengths of the pipe line and with segregation comes flow or pumping problems and blockages. We must therefore improve flowability, maintain or improve strength but also ensure that the fill remains coherent and non-segregating. Modern superplasticisers in combination with viscosity modifying admixture can achieve this, by increasing solids content and/or reducing water content and maintaining the same flow and workability.

\subsection{Superplasticisers}

The effects of superplasticisers are mainly used to create the same flow or workability but with a higher solids content or reduced water content. Often this can result in binder reduction for a similar-strength fill. As a result superplasticisers are sometimes referred to as cost effective binder-reducing admixtures, yet this is not all we can gain from these admixtures.

In operations where high pumping pressures occur, standard control measures to keep pipeline pressures within a certain range rely on additional water being added, often manually. Water will definitely make the fill more fluid and decrease pressure in the pipes but the higher water:binder ratio will influence and change the fill properties downstream. Namely, higher water:cement ratios will cause lower strength, which is not desirable.

Segregation may also occur, causing blockages in some cases. Ultimately, for the fill to reach the required strength performance, increasing the binder content can achieve this. Nevertheless, binder costs are already the major cost in most backfill systems, and additional binder costs versus strength increase in a fill is not a linear function, it is often quite the opposite. Indeed, adding binder above a certain level can often actually prove detrimental to the fill strength, due to additional water and the solids content relationship required to achieve a transportable fill. Practically, to maintain a required flow at the plant, water is added and hence final strength will be negatively affected.

Superplasticisers therefore can improve the flowability, will not change the ultimate strength and can reduce binder content to provide a cost-effective solution. Alternatively, the same workability and flow can be achieved with the same or higher binder/solids content to increase the fill strength.

Often, the final goal of backfill optimisation is not just recognised through binder cost reduction; there are other scenarios and problems requiring admixture solutions. For instance, if a backfill operation needs to gain fill strengths faster due to the mining sequence, then superplasticising admixtures can provide such a solution, by maintaining adequate flow with higher binder or solids content as compared to the reference or existing mix design. The net result is higher fill strengths in a shorter time, to allow mining extraction sooner. In these scenarios, the overall cost of the backfill operation will be greater than a standard cost, but the Net Present Value (NPV) of the total mining operation will be better due to the shorter mining cycle.

\subsection{Viscosity modifying admixtures}

In a backfill system such as described previously (a system with low fines, relatively low solids content or with a significant rate of segregation), viscosity modifying admixtures (VMA) can significantly improve the fill properties, providing a lower rate of segregation, which will have a significant role and impact on flowability, especially in the horizontal flow sections of the transportation system.

VMAs can greatly improve in situ properties of the fill by keeping fines and binder within the fill mass but allowing drainage of water out of the fill without binder loss. Various families of VMAs can be used to flocculate binders and/or change the liquid phase properties of the system. 
For "gap graded" materials, VMAs are essential to lessen the effects of this gap in the distribution of fines within the entire volume of the fill. This will improve the homogeneity of the fill and significantly reduce the 'layer structure' of the fill. This is especially recognised in many hydraulic fills and in cemented aggregate fills that are gap graded. Self-levelling properties can be gained, as these admixtures provide more flowable fills with lower beach angles and better placeability. From Figure 2 it can be seen that the fill treated with VMA has lower beach angle and no layer structure (ASTM C 230-90, 1997).

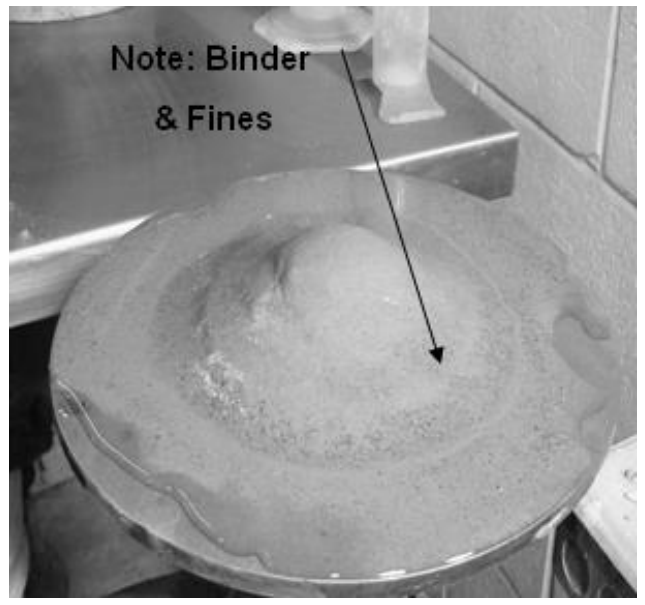

Untreated sample

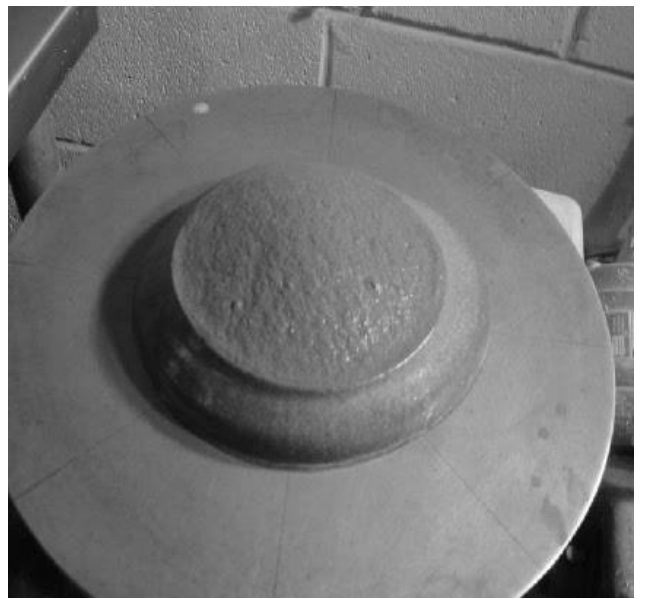

Sample treated with VMA

Figure 2 Effect of VMA on hydraulic sample: beach angle

VMAs could be equally used in paste or low-density paste for similar reasons, or as a pumping aid. As a pumping aid, the VMA can reduce pump pressure in the pipelines which could be one critical parameter for a backfill operation which aims to increase pumping distances.

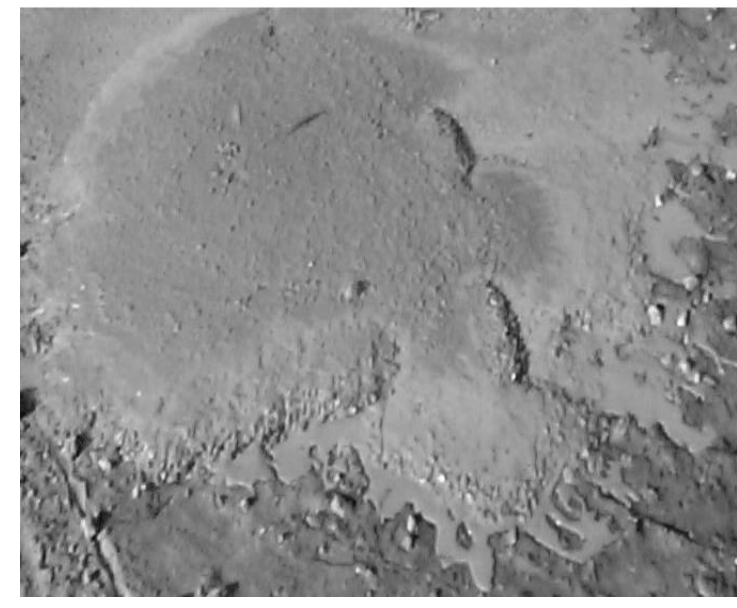

Untreated sample

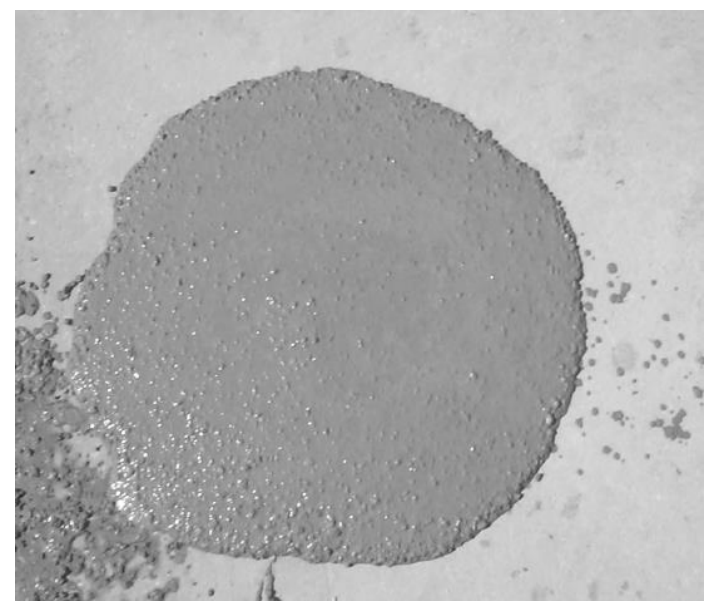

Sample treated with VMA

Figure 3 Effect of VMA on the hydraulic fill sample: segregation

Summarising, VMA technology can:

- produce a coherent and homogeneous fill

- reduce segregation, especially in horizontal sections of the pipeline which can often define the maximum distance for pumping

- reduce the friction in the pipeline and increase the distance, the fill can be pumped or flow via gravity under the same hydraulic head. 
It should be understood that this admixture can work and benefit many backfill systems; however it will be an additional cost to the standard operation. Binder price and cost of backfill operations basically will determine the possibility of implementing this technology in a backfill system. Binder reduction using a superplasticiser may show economically that VMAs can be used with no additional cost to the system.

\subsection{Hydration control and retarding admixtures}

Specialised binder hydration control and retarding admixtures are available for backfill and have been in use in backfill longer than any other type of backfill admixture. However, even for these admixtures, all possibilities have not been fully exploited. Hydration of the cement binder can be stopped totally for hours or even days if the system requires. A variety of admixtures can be used for this result. Providing longer open times and retarding initial setting was the main goal of these admixtures for many years, but it has been proven that some retarders can also act as minor water reducers. It was also found in cemented rock fill applications that these admixtures improve the final (overall) fill strengths.

The explanation can be found in the fact that retarders change the fill rheology by two mechanisms. These are:

- retarding initial hydration and setting — strong co-relationship

- improving rheology — by acting as a low water reducing admixture.

Initial hydration occurs relatively early when the binder first makes contact with water (first minutes of contact). This initial hydration causes a gelling effect which would assist in improved setting time if the mix was left alone. Although in practice, this initial hydration is destroyed at the plant by adding extra water to improve flowability and then transported many kilometres such that the initial hydrate structures are destroyed. This is lost energy out of the system.

The initial hydration reaction energy is deferred (but not lost) when using hydration control or retarding type admixtures. Thus using correct dosages of retarder, even when the fill is several hours old, and in place, the fill setting due to cement hydration can be improved compared to no retarder use. This does sound strange (a retarder actually accelerating the speed of strength development), but this has been found to be the case in many of BASF/MEYCO laboratory experiments.

\section{$5 \quad$ Case studies}

\subsection{Mine A}

A good illustration of the increased strength development and hydration control described can be found in test results presented here regarding samples from Mine A. Mine tailings with sand were blended in order to get a homogeneous sample. The moisture contents of samples were measured and a correction factor was applied in the calculation formula for mix design.

The hydration control admixture dosage rates are as shown in Table 1 . The paste backfill, with a sand:tailings ratio of 55:45, was prepared at a solids content of $83 \%$, with $4.5 \%$ binder content. The paste fill was mixed and placed in a room at a temperature of $33^{\circ} \mathrm{C}$. The consistency (slump) measurements (ASTM 143/143M-10a) were taken at elevated temperature. The paste samples were mixed again for 30 seconds prior to each extended consistency measurement.

Compressive strength test specimens $(75 \times 150 \mathrm{~mm}$ cylinders $)$ were cast and stored at the elevated temperature $\left(35^{\circ} \mathrm{C}\right)$ and controlled humidity $(95 \%$ humidity) until testing. The testing matrix and results are presented in Table 1. 
Table 1 Testing matrix - backfill mix design for Mine A

\begin{tabular}{|c|c|c|c|c|c|}
\hline & \multirow{2}{*}{$\begin{array}{c}\text { Control - No } \\
\text { Admixture } \\
0 \mathrm{~mL} / \mathrm{t}\end{array}$} & \multicolumn{4}{|c|}{ With Admixture - MEYCO Minefill 701} \\
\hline & & $800 \mathrm{~mL} / \mathrm{t}$ & $1,000 \mathrm{~mL} / \mathrm{t}$ & $1,200 \mathrm{~mL} / \mathrm{t}$ & $1,400 \mathrm{~mL} / \mathrm{t}$ \\
\hline Time & Slump, mm & Slump, mm & Slump, mm & Slump, mm & Slump, mm \\
\hline Initial & 222 & 222 & 222 & 222 & 229 \\
\hline $2 \mathrm{hrs}$ & 178 & 222 & 222 & 222 & 222 \\
\hline $4 \mathrm{hrs}$ & 121 & 178 & 216 & 222 & 229 \\
\hline $6 \mathrm{hrs}$ & No test & 127 & 178 & 216 & 222 \\
\hline $8 \mathrm{hrs}$ & No test & No test & 146 & 178 & 222 \\
\hline \multicolumn{6}{|c|}{ Unconfined compressive strength (UCS), average (MPa) } \\
\hline 2 days & 1.35 & 1.38 & 1.15 & 1.06 & 0.845 \\
\hline 28 days & 3.25 & 3.77 & 3.94 & 4.55 & 4.71 \\
\hline 180 days & 3.9 & 4.8 & 5.1 & 5.4 & 5.8 \\
\hline
\end{tabular}

For an easier interpretation, the slump results from Table 1 are presented in Figure 4, while Figure 5 shows the UCS results.

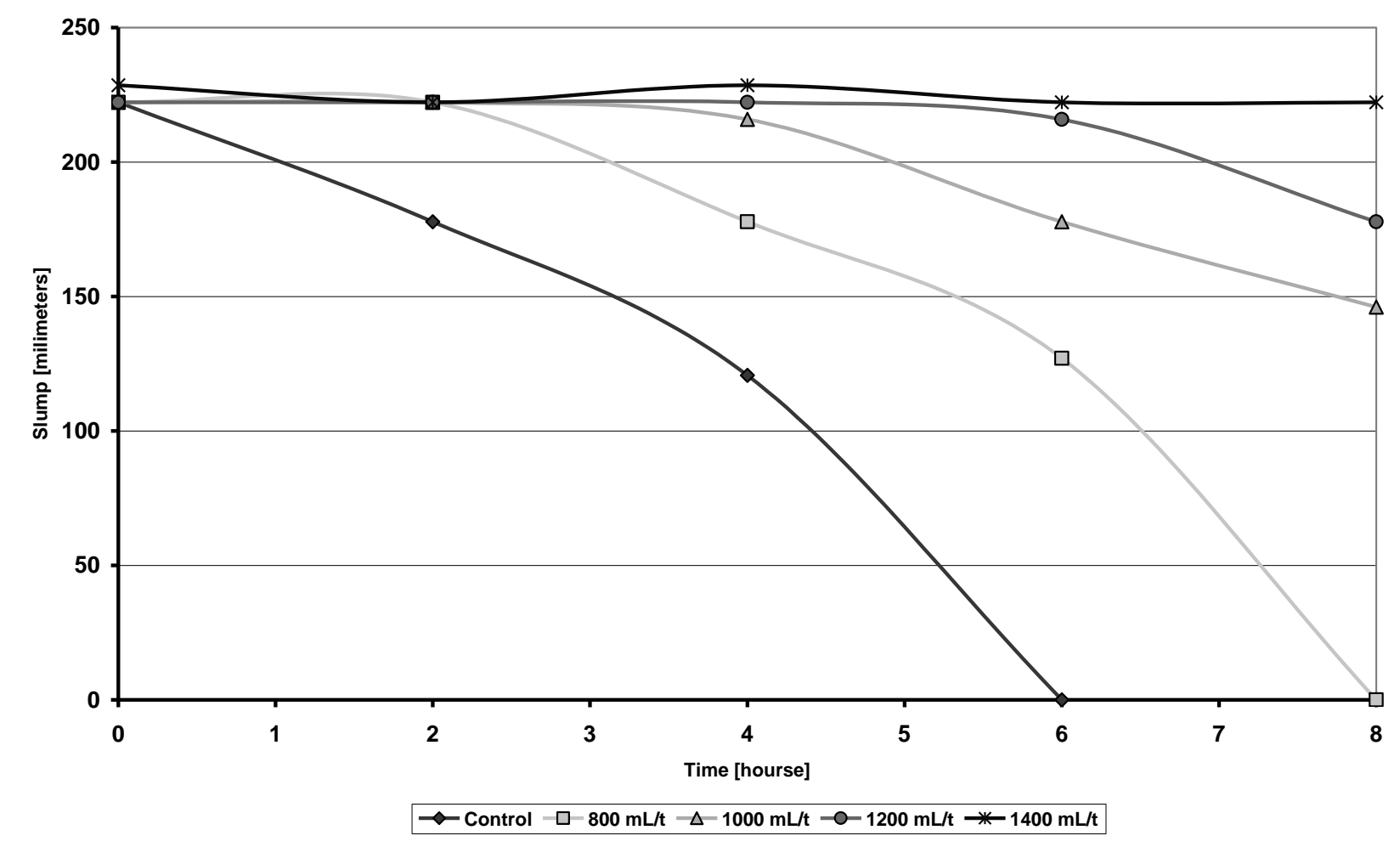

Figure 4 Slump retention with variable dosage of admixture MEYCO Minefill 701 


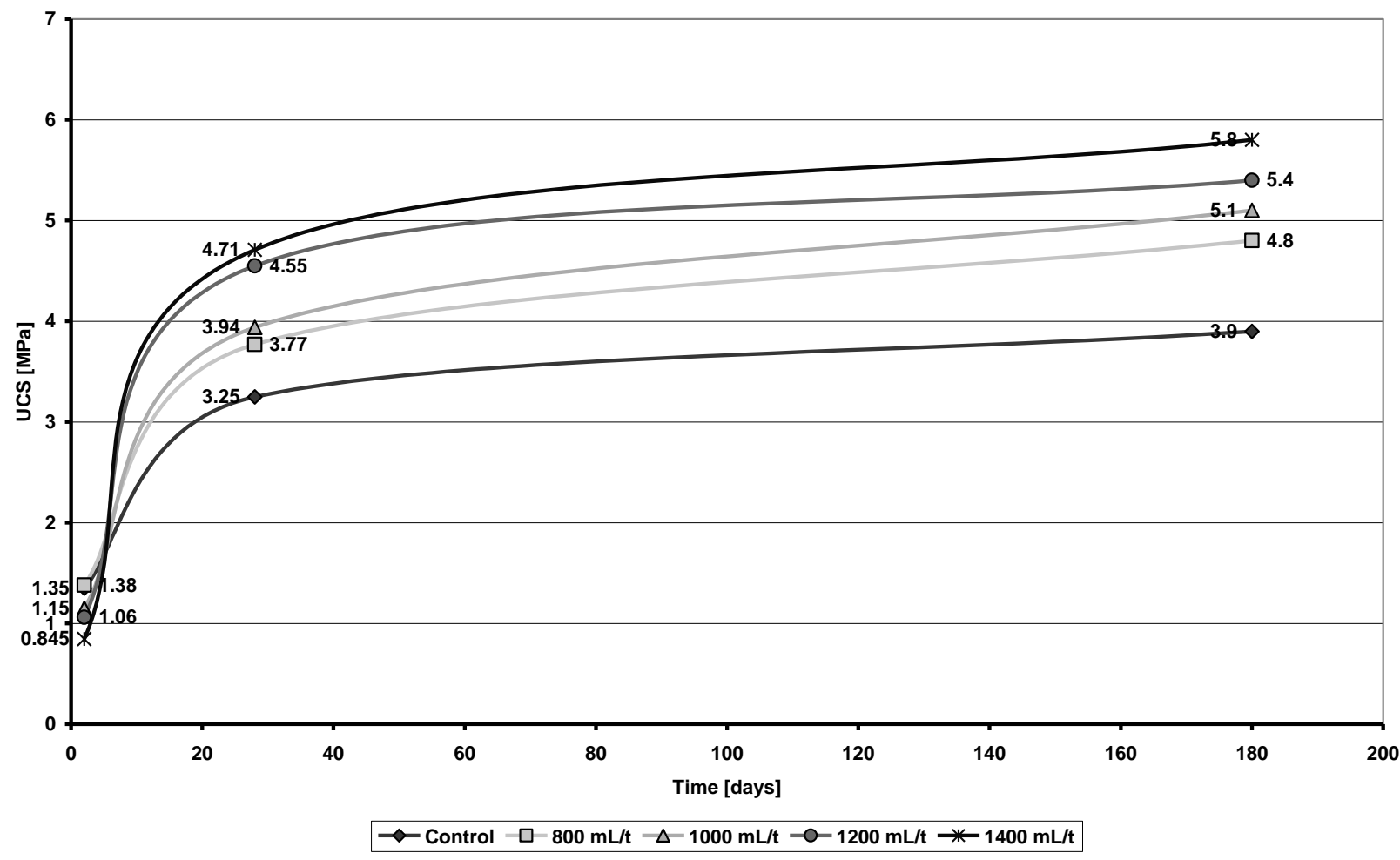

Figure 5 Strength development of backfill with variable dosage of admixture MEYCO Minefill 701

As shown in Figures 4 and 5, it is clear that this admixture can retain longer flow or workability (open time) successfully at elevated temperatures, but at the same time provide significantly higher strength.

\subsection{Mine B - looking at yield stress and strength development}

Tailings from this mine were dried and homogenised in order to get a representative sample. Water and admixture were blended and binder was added to the blend and mixed for 30 seconds. Tailings were added into the mixer and mixed for another 60 seconds, the mixer was stopped, and the fill was manually remixed and then the mixer was restarted and the fill was mixed for 90 seconds (total time of mixing was 3 minutes). The fill rested for 3 minutes and was then placed into the Rheometer cup. The main goal of this testing was for binder optimisation. After yield stress measurements were completed, the fill was mixed again for 60 seconds and samples were cast for UCS measurements. Curing was carried out at $30^{\circ} \mathrm{C}$ in a room with $95 \%$ relative humidity.

Using the representative sample, various mixes were made varying the cement content, and the solids content, using admixtures and without admixtures. The main goal of testing was for binder optimisation.

Table 2 Testing matrix - backfill mix design for Mine B

\begin{tabular}{lcc}
\hline & Control Mix Design & Mix Design with Admixture \\
\hline Solids content, $\%$ & 76 & 78 \\
Binder contents, $\%$ & $3 ; 4 ; 5$ and 6 & $3 ; 4 ;$ and 5 \\
Tailings, $\%$ & 100 & 100 \\
$\begin{array}{l}\text { Admixture dosage, } \mathrm{mL} / \mathrm{t} \text { (total } \\
\text { backfill or wet tonne) }\end{array}$ & 0 & 500 \\
\hline
\end{tabular}

Results of rheological measurements done with a rheometer (vane sensor) are presented in Figure 6, and UCS values measured at different curing times are presented in Figure 7. 


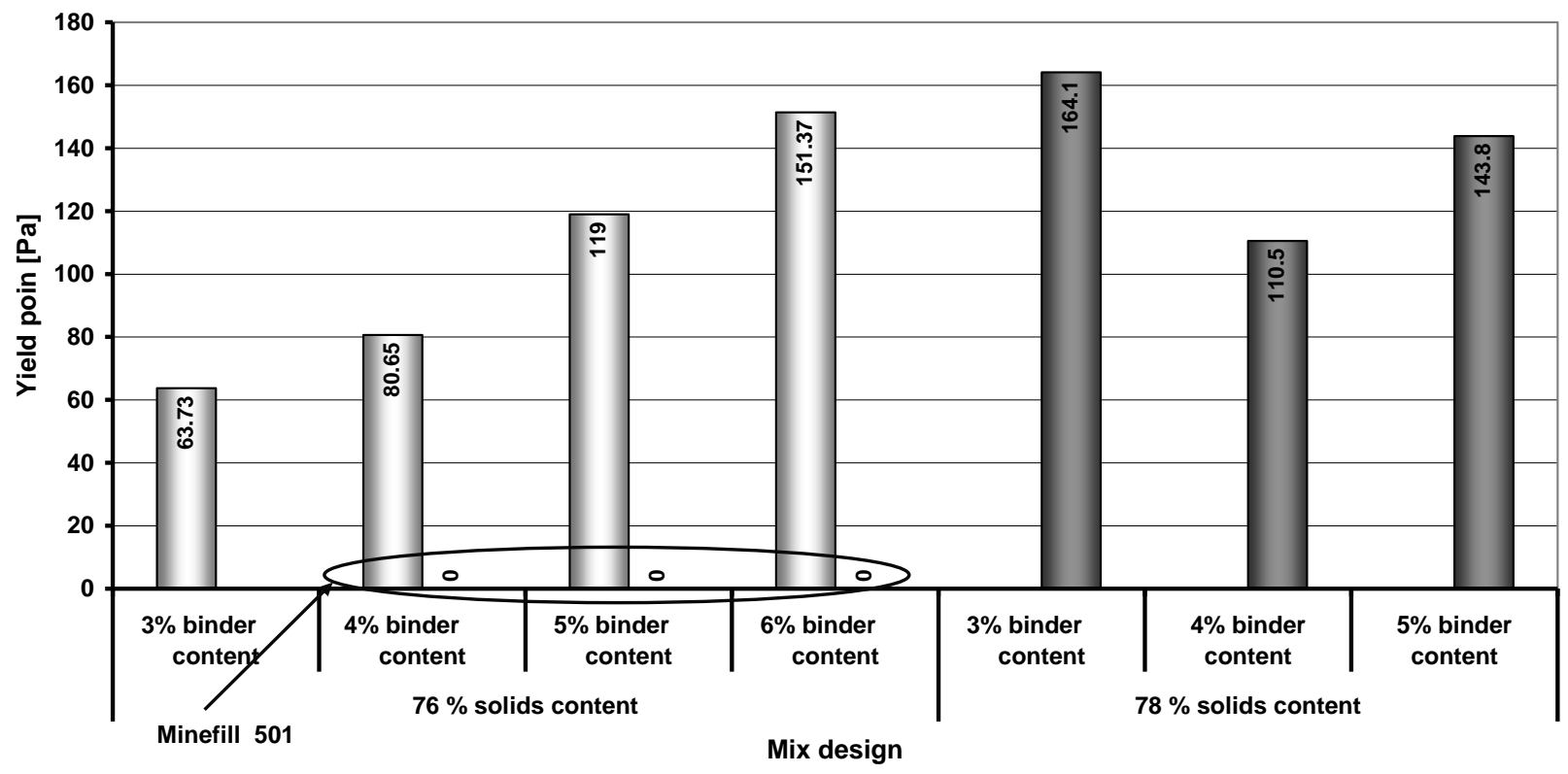

$\square$ Control $\square$ Minefill 501

Figure 6 Yield stress values as a function of mix design (different solids contents, various binder contents of mix, with and without admixture). Admixture dosage $500 \mathrm{~mL} / \mathrm{t}$ of total backfill

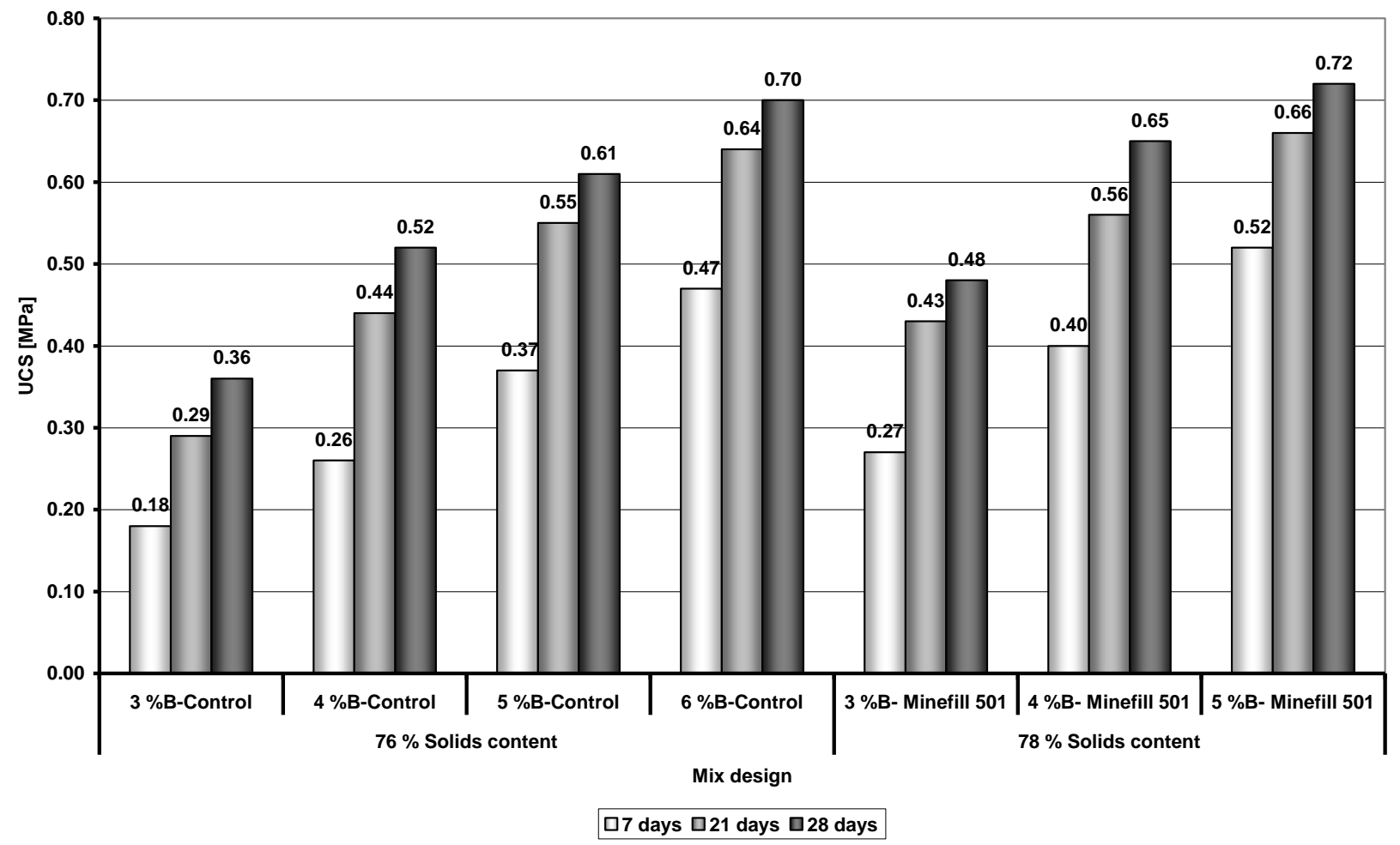

Figure 7 UCS development as a function of mix design

From this data, we can conclude that the admixture does improve flowability of fill. This is represented in Figure 6, where on the left side of the chart (showing samples with $76 \%$ solids content) we observe an increase of yield point as a function of binder content for the control samples. At the same time it can be said that for the same mix designs the yield stress with admixtures was not measurable. This is represented with "zero" values on abscissa axis (ellipse, Figure 6). It is important to highlight that these values are showing low yield stress which was not measurable with the existing set up of the device (HAAKE VT550, sensor 
type FL100) and absolutely not true values. We can then conclude that the mix designs with admixture were very fluid compared to the control samples. On the right side of graph the solids content is elevated to $78 \%$ and it can be seen that the fill has the same or similar yield stress as the control at lower solids content $(76 \%)$.

The UCS results in Figure 7 show that the mix design with admixture, a lower binder content, and higher solids content, can replace a mix design without admixture that has a higher binder content and lower solids content without an impact on strength. It must be remarked that the flow characteristics of the fill were the same in both cases. For economical reasons, and to match project request, in order to find cost effective solutions control samples are compared at lower solid content and higher binder content with samples at higher solid content and lower binder and admixture.

We can conclude that the admixture MEYCO Minefill 501 can:

- Drastically reduce yield stress at $76 \%$; using the admixture at $76 \%$ solids there is practically zero yield stress.

- Improve the flowability of the fill.

- Enable a higher solids content to be used: $78 \%$.

- Enable a 4\% binder content mix with admixture to have greater UCS than a 5\% binder control mix.

- Enable a 5\% binder content mix with admixture to have greater UCS than a $6 \%$ binder control mix.

Hence, in this example we see the multiple benefits of using an admixture in a paste fill. It can equally serve in this case as a rheology modifier, decreasing pressure in the pipes for the same solids content if this is required, and it can thus be used as an additional option for mine cycle improvement - i.e. the required strength can be achieved in shorter periods of time. Significant improvements in the flow properties of the fill with admixture, compared to the control mix represented in Figure 6, can be used to increase solids content of mix with admixtures that maintain the same flow parameters as the control mix without cut off on binder. Increments of UCS over time is then logical as the water:cement ratio is lower for the mix design with admixture at higher solids content compared to the control mix at lower solids content. In the case presented in Figure 6 we have slightly higher values of yield stress with mix designs at higher solids content with admixtures as compared to control, but it could be assumed that a slight correction in solids content will give the same flow. Then we can assume from existing data that with the same binder content, a higher strength could be gained over time with admixtures.

The physical difference in flow properties of these mixes can be seen in Figure 8 . 


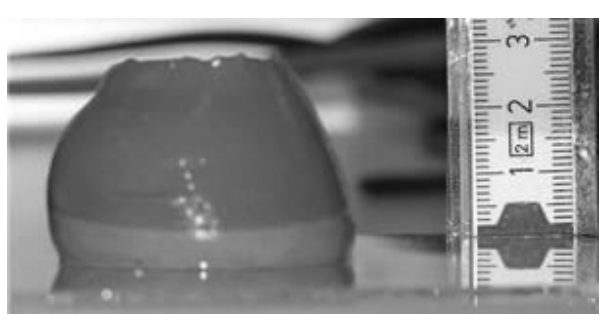

Slump of fill without admixture

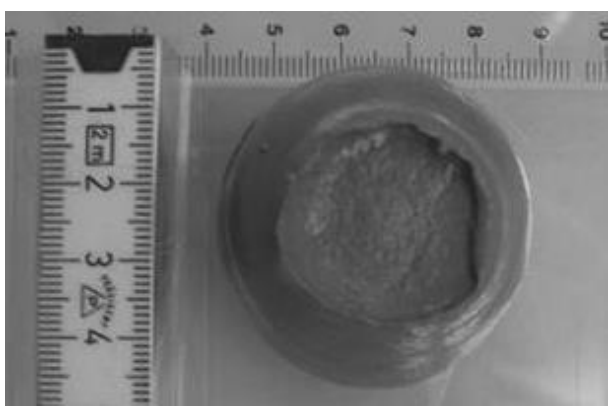

Spread of fill without admixture

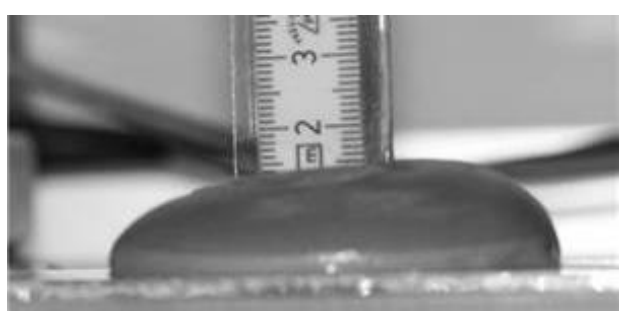

Slump of fill with admixture

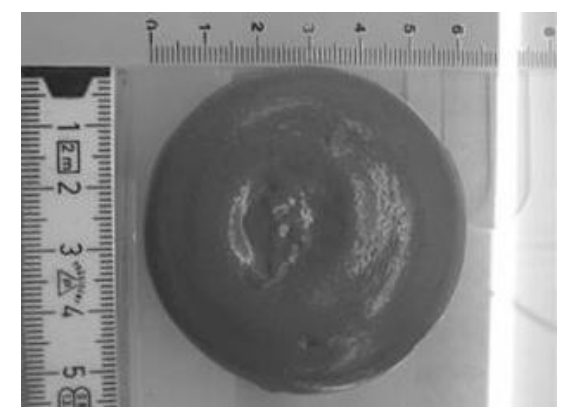

Spread of fill with admixture

Figure 8 Mini slump test used for visual checking of flow properties (mould dimensions $\mathbf{H}=\mathbf{5 0} \mathbf{~ m m}$ and $\mathrm{D}=\mathbf{3 0} \mathbf{~ m m}$ )

\section{Conclusion}

The key for successful implementation of admixtures in a backfill operation lies in a good understanding of the individual process (specification about length, transportation mode - gravity feed, pumps - temperature, etc.). The key goals which are required to be solved at the mine need to be agreed (segregation, pumping pressure, binder optimisation, etc.). A good understanding of material properties (tails, binder and water) is required from the chemistry aspect.

With this information available, possible appropriate admixtures can be selected but only testing methods that are related to the backfill system (paste, hydraulic fill or cemented rockfill) can prove the effectiveness of the admixture. There is not, and will not be in the near future, a universal admixture for all applications and all types of materials (different tailings, binder or water types).

Some admixtures are more robust in difficult chemical conditions than others (in other words they are less affected by other chemicals in the "backfill soup"), however their potency is often not as great.

Generally, the more robust the admixture the less effectively they perform. Or more precisely, if a very effective admixture is required with high performances for a certain application, this seems to require a more tailor-made type of admixture for known parameters and controlled conditions. For these reasons, good knowledge of all the main backfill parameters stated above will lead to the most suitable and cost-effective choice of admixture type. Better exchange of information and knowledge between the backfill operators and chemical company will lead to better understanding and better performances of admixtures in the future.

What should be done at the mine to recognise and adopt the right admixtures and/or right combination? The approach has to be systematic, and involve both, the mine, its consultants and the chemical company.

Firstly, all the desired feasible goals have to be clearly defined by the mine and understood by all. The priorities need to be established, and any perceptions or misconceptions fully explained and understood by everyone. Chemical solutions exist in many applications, but not all.

Secondly, material characterisation and analysis must be properly done in order to recognise problem areas, which can either be eliminated or dealt with chemically. The material characterisation process is long and tedious, and detailed investigation on all the materials used in the fill production is essential. There are no short cuts, as each parameter can play a significant role with varying degrees of magnitude from case to case. Changes in material properties must be evaluated (different parts of the orebody, different parts of the 
tailings pond for dry excavated tailings, PSD changes, degrees of degradation and oxidation, etc.). A highlevel sampling procedure is important to provide accurate samples that should be representative of the mine backfill mix.

The mechanical or physical side of the system should be very well known, especially mixers, pumps, delivery system, barricades, etc. Pipeline pressures are just one example. In situ fill needs and requirements must be well known and specified, such as fill strength against time. However, this is normally checked via samples taken at the surface and samples retrieved by coring underground.

BASF's experience in the labs and in the field tests with their industrial partners has shown that by using admixtures they can provide a chemical solution that can be both economical and advantageous for the mine. Often the chemical solution involves a combination of chemical admixtures to achieve the desired results. The most common combinations that have been used in the past involve superplasticisers and VMAs, superplasticisers and retarders, and retarders with VMAs.

Once again, cost effective analysis is normally the determining factor for any process and certainly for backfill. In a backfill system there are still hidden values which should be recognised and evaluated. Admixtures are definitely an additional cost but it should also be known what they can do and where the hidden benefits are.

It should be clear that limitations exist, and that present admixtures may not be suitable in all backfill cases. Continuous development will mean that new and more effective admixtures are becoming available. This should lead to more sophisticated and beneficial technologies in the future backfill industry.

\section{References}

Archibald, J.F., DeGagné, D.O., Lausch, P. and De Souza, E.M. (1995) Ground waste glass as a pozzolanic consolidation agent for mine backfill, CIM Bulletin, Vol. 88, No. 909, pp. 80-87.

ASTM C 230-90 (1997) Standard specification for Flow Table for use in Tests of Hydraulic Cement, 1997 Annual Book of ASTM Standards, American Society for Testing and Materials (ASTM), Philadelphia Vol. 04.01, pp. 182-186.

ASTM C 143/143M-10a Standard test method for slump of hydraulic-cement concrete, in Annual Book of ASTM Standards, American Society for Testing and Materials (ASTM), Philadelphia, Vol. 04.02.

Aylmer, F.L. (1973) Cement properties related to the behaviour of cemented fill, in Proceedings Jubilee Symposium on Mine Filling, Mount Isa, North West Queensland Branch, The AusIMM, August, pp. 59-63.

Belem, T. and Benzaazoua, M. (2007) Design and application of underground mine paste fill technology, Geotechnical and Geological Engineering, Vol. 26, No. 2, pp. 147-174.

Donovan, J., Dawson, J. and Bawden, W.F. (2007) David Bell Mine Underhand Cut and Fill Sill Mat Test, Minefill 2007 Symposium, April 29 - May 3, Montreal, Quebec, Canada.

Farzam, H., Rispin, M. and Karlson, R. (1998) The Use of Unique Admixture Technologies in Mining Backfill Technology Description and Case Histories, Minefill 98, in Proceedings Sixth International Symposium on Mining with Backfill, AusIMM, Carlton Victoria, pp. 71-75.

Gay, F. and Constantiner, D. (1998) Additives for improving paste backfill mixes, Tailings and Mine Waste '98, in Proceedings 5th International Conference, Fort Collins, Colorado, 26-28 January, A.A. Balkema, Rotterdam, The Netherlands, pp. 159-166.

Klein, K. and Simon, D. (2006a) Effect of specimen composition on the strength development in cemented paste backfill, Canadian Geotechnical Journal, NRC Research Press, Journal 43, pp. 310-324.

Klein, K. and Simon, D. (2006b) Electromagnetic properties of cemented paste backfill, Journal of Environmental and Engineering Geophysics, GeoScienceWorld, Vol. 11, pp. 27-41.

Nieminen, P. and Seppanen, P. (1983) The use of blast-furnace slag and other by-products as binding agents in consolidated backfilling at Outokumpu Oy's mine, in Proceedings International Symposium of Mining with Backfill, Luleå, Balkema, Rotterdam, 7-9 June, pp. 49-58.

Ramachandran, V.S. (1995) Concrete Admixtures Handbook, Properties, Science, and Technology, Second Edition, Noyes Publications, Park Ridge, New Jersey, pp. 286-506; 994-1006.

Thomas, E.G. (1973) A review of cementing agents for hydraulic fill, in Proceedings Jubilee Symposium on Mine Filling, Mount Isa, North West Queensland Branch, The AusIMM, August, pp. 65-75.

Yu, T.R. and Counter, D.B. (1988) Use of fly ash in backfill at Kidd Creek Mines, CIM Bulletin, Vol. 81, No. 909, pp. 44-50.

Wang, C., Padrutt, A. and Millette, D. (2002) Improvement of cemented backfill properties by using admixtures, in Proceedings 7th Annual GSE Symposium - Geotechnique in The Mining Industry, March. 